\title{
Fatty Acids of Leptotrichia buccalis: Taxonomic Implications
}

\author{
By TOR HOFSTAD ${ }^{1 *}$ AND ERIK JANTZEN ${ }^{2}$ \\ ${ }^{1}$ Department of Microbiology and Immunology, The Gade Institute, University of Bergen, \\ N-5016 Haukeland sykehus, Bergen, Norway \\ ${ }^{2}$ National Institute of Public Health, Oslo, Norway
}

(Received 7 April 1981)

Fatty acids of five strains of Leptotrichia buccalis were examined by gas-liquid chromatography. The strains showed identical patterns, characterized by the presence of $n$-hexadecanoate, octadecenoate and 3-hydroxytetradecanoate as major acids. The general fatty acid pattern showed a distinct similarity to that of Fusobacterium species.

\section{INTRODUCTION}

The Gram-negative oral organism Leptotrichia buccalis is currently classified as a member of the family Bacteroidaceae (Rogosa, 1974). With respect to morphology and biochemical properties the organism seems to form a well circumscribed species. However, some intraspecies heterogeneity does exist. Several strains can grow in air in the presence of $\mathrm{CO}_{2}$, whereas others are obligately anaerobic. Also, analyses of cell wall lipopolysaccharides showed differences amongst the strains examined (Birkeland \& Hofstad, unpublished observations).

Gas-liquid chromatography (g.l.c.) of cellular fatty acids has proved useful in differentiating facultative as well as anaerobic bacteria (Lechevalier, 1977; Shaw, 1974). We have recently examined the fatty acid composition of several species of Fusobacterium by means of g.l.c. (Jantzen \& Hofstad, 1981). The same technique has now been used in a study of Leptotrichia buccalis. A comparison is made with Fusobacterium nucleatum, since a phylogenetic relationship between these two organisms has been suggested (Page \& Krywolap, 1977).

\section{METHODS}

Strains and cultivation. Leptotrichia buccalis strains ATCC 14201 and ATCC 19616 were received from W. Kondo, Niigata, Japan. Strains L11, L92 and L97 were isolated from saliva of healthy human individuals using blood agar (Hofstad, 1967), or a selective medium (Walker et al., 1979), and anaerobic incubation. Strains ATCC 14201 and L97 are obligately anaerobic; the other three strains grow in air in a $\mathrm{CO}_{2}$ incubator. In other respects, the strains have similar cultural and physiological properties.

The bacteria were cultivated on blood agar plates (Difco Tryptone agar supplemented with $0.001 \%(\mathrm{w} / \mathrm{v})$ menadione and $7 \%(\mathrm{v} / \mathrm{v})$ human blood $\mathrm{l}$ at $37^{\circ} \mathrm{C}$ for $72 \mathrm{~h}$ in a deoxygenated $\mathrm{CO}_{2}$ atmosphere (BBL GasPak jars). Bacterial growth was washed from the blood agar using a right-angled glass rod and sterile water. Biomass was sedimented by centrifugation at $3000 \mathrm{~g}$ for $20 \mathrm{~min}$, washed twice with distilled water, freeze-dried and stored under nitrogen in closed vials at $-20^{\circ} \mathrm{C}$.

Chemicals, chemical procedures and gas-liquid chromatography. Solvents of analytical grade were distilled before use. The $2 \mathrm{M}-\mathrm{HCl}$ in methanol was obtained by bubbling dry $\mathrm{HCl}$ gas (Fluka, Buchs, Switzerland) into dried methanol until saturated, and subsequent dilution. Fatty acid methyl ester standards were obtained from Applied Science Laboratories, State College, Pa., U.S.A.

Dried bacterial cells $(1-10 \mathrm{mg})$ were treated with $2 \mathrm{M}-\mathrm{HCl}$ in methanol, and the dimethyl acetals were removed as previously described (Jantzen \& Hofstad, 1981). After trifluoroacetylation of hydroxylated fatty acids (Jantzen \& Hofstad, 1981) the fatty acid methyl esters were analysed on a Hewlett-Packard 5710 gas chromatograph 
Table 1. Fatty acid composition of Leptotrichia buccalis

\begin{tabular}{|c|c|c|c|c|c|c|c|c|c|}
\hline \multirow[b]{2}{*}{ Strain } & \multicolumn{9}{|c|}{ Fatty acid composition* $(\%, w / w$, of total in strain $)$} \\
\hline & $12: 0$ & $14: 0$ & $\begin{array}{c}3-\mathrm{OH} \\
14: 0\end{array}$ & $15: 0$ & $16: 1$ & $16: 0$ & $\mathrm{X} \dagger$ & $18: 1$ & $18: 0$ \\
\hline ATCC 14201 & 0.4 & $5 \cdot 1$ & $15 \cdot 1$ & 0.6 & $2 \cdot 8$ & $35 \cdot 2$ & $2 \cdot 0$ & $35 \cdot 2$ & $3 \cdot 7$ \\
\hline ATCC 19616 & 0.7 & $4 \cdot 7$ & $15 \cdot 5$ & 0.4 & $2 \cdot 3$ & $41 \cdot 1$ & 1.0 & $32 \cdot 1$ & $2 \cdot 2$ \\
\hline L11 & $1 \cdot 6$ & $6 \cdot 0$ & $12 \cdot 7$ & 0.4 & $2 \cdot 8$ & $42 \cdot 4$ & 1.4 & 30.6 & $2 \cdot 7$ \\
\hline L92 & $\mathrm{tr}$ & $4 \cdot 1$ & $17 \cdot 1$ & 0.6 & 0.9 & 42.5 & 1.5 & 29.5 & 4.0 \\
\hline L97 & 0.6 & $6 \cdot 5$ & 18.8 & 0.9 & 2.9 & $36 \cdot 3$ & $1 \cdot 1$ & $26 \cdot 8$ & 3.9 \\
\hline
\end{tabular}

$\operatorname{tr}$, less than $0.1 \%$.

* The figure before the colon indicates the number of carbon atoms in the chain, that after the colon denotes the number of double bonds (the position of the double bonds has not been determined); 3-OH indicates the presence of a 3-hydroxyl group.

$\dagger$ A compound which co-chromatographed with octadecadienoate.

equipped with a flame ionization detector, capillary column control (Hewlett-Packard 18740), and a methyl silicone-coated capillary column $(25 \mathrm{~m} \times 0.2 \mathrm{~mm}$ SE-30 fused silica; Hewlett-Packard) as previously described (Jantzen \& Hofstad, 1981). The chromatograms and analytical results were provided by a digital recorder/ integrator (Hewlett-Packard 3390A).

The fatty acid methyl esters were identified by comparison of retention data with those of standards. Hydroxy fatty acids were recognized by trifluoroacetylation and rechromatography (Jantzen \& Hofstad, 1981).

All structural elucidations were verified by gas chromatography/mass spectrometry [Hewlett-Packard 5992A instrument equipped with a methyl silicone-coated capillary column $(25 \mathrm{~m} \times 0.5 \mathrm{~mm}$ CP Sil 5 glass capillary column; Chrompack)] (Jantzen \& Hofstad, 1981).

\section{RESULTS}

All five test strains of Leptotrichia buccalis exhibited a very similar fatty acid composition characterized by relatively large amounts of $n$-hexadecanoate $(16: 0)$, octadecenoate $(18: 1)$ and 3-hydroxytetradecanoate (3-OH-14:0) (Table 1). Present in all the strains, but in smaller amounts, were $n$-dodecanoate $(12: 0), n$-tetradecanoate $(14: 0), n$-pentadecanoate $(15: 0)$, hexadecenoate $(16: 1), n$-octadecanoate $(18: 0)$, and a constituent which cochromatographed with octadecadienoate $(18: 2)$ (Jantzen \& Hofstad, 1981). Cyclopropanesubstituted acids and methyl-branched isomers could not be detected. This general fatty acid profile for $L$. buccalis was similar to the profiles for Fusobacterium species (Jantzen \& Hofstad, 1981).

\section{DIS CUSSION}

Leptotrichia buccalis has a fatty acid composition characteristic of a Gram-negative bacterium. The close similarity in fatty acid patterns amongst the five strains examined substantiates the designation of $L$. buccalis as a species.

There are distinct similarities between L. buccalis and Fusobacterium nucleatum (Table 2). Both organisms appear in Gram-stained smears as Gram-negative fusiform rods. The guanine plus cytosine $(\mathrm{G}+\mathrm{C})$ contents of the DNA are similar in both organisms $(25-27 \%)$ and unusually low (Page \& Krywolap, 1976). With the exception of 3-hydroxyhexadecanoic acid, which is a taxonomic marker for F. nucleatum (Jantzen \& Hofstad, 1981), the two organisms have a grossly similar fatty acid pattern. The relative amount of octadecenoic acid is higher in $L$. buccalis than in $F$. nucleatum, whereas $F$. nucleatum contains relatively more $n$-tetradecanoic acid. The principle phenotypic differences between the two organisms are that $L$. buccalis metabolizes a range of different sugars whereas $F$. nucleatum is asaccharoclastic, and, as indicated above, L. buccalis is not an obligately anaerobic organism. 
Table 2. Main characteristics of Leptotrichia buccalis and Fusobacterium nucleatum

Characteristics

Cell morphology

Habitat

Diamino acid of the peptidoglycan*

Main fatty acids

Fermentation of carbohydrates

Main metabolic end-product

Relation to oxygen

$\mathrm{Mol} \% \mathrm{G}+\mathrm{C} \ddagger$
Leptotrichia buccalis

Fusiform

Human oral cavity

Diaminopimelic acid

$16: 0,18: 1,3-\mathrm{OH}-14: 0$

Saccharoclastic

Lactic acid

Facultative or anaerobic

25
Fusobacterium nucleatum

Fusiform

Human oral cavity

Lanthionine

$14: 0,16: 0,3-\mathrm{OH}-14: 0$ (3-OH-16:0†)

Asaccharoclastic

Butyric acid

Anaerobic

25-27

* From Davis \& Baird-Parker (1959) and Vasstrand et al. (1979).

† Specific to F. nucleatum, not found in other species of Fusobacterium (Jantzen \& Hofstad, 1981).

$\ddagger$ From Page \& Krywolap (1976).

The taxonomic position of $L$. buccalis is still uncertain, but awaiting further data, the present position in the family Bacteroidaceae should be maintained.

The study was supported in part by the Norwegian Research Council for Science and the Humanities.

\section{REFERENCES}

Davis, G. H. G. \& BAIRd-PARKer, A. C. (1959). Cell-wall composition of Leptotrichia spp. Nature, London 183, 1206-1207.

HofSTAD, T. (1967). An anaerobic oral filamentous organism possibly related to Leptotrichia buccalis. 1. Morphology, some physiological and serological properties. Acta pathologica et microbiologica scandinavica 69, 543-548.

JANTZEN, E. \& HoFsTAD, T. (1981). Fatty acids of Fusobacterium species: taxonomic implications. Journal of General Microbiology 123, 163-171.

LeCheVALIER, H. (1977). Lipids in bacterial taxonomy - a taxonomist's view. CRC Critical Reviews in Microbiology 5, 109-210.

Page, L. R. \& KRywolap, G. N. (1976). Determination of the deoxyribonucleic acid composition and deoxyribonucleic acid-deoxyribonucleic acid hybridization of Fusobacterium fusiforme, Fusobacterium polymorphum, and Leptotrichia buccalis: taxonomic considerations. International Journal of Systematic Bacteriology 26, 301-304.

Page, L. R. \& Krywolap, G. N. (1977). Oral
Fusobacterium, Leptotrichia and Bacterionema: I. Historical survey and taxonomic considerations. Journal of the Baltimore College of Dental Surgery 32, 12-24.

Rogosa, M. (1974). Genus III. Leptotrichia Trevisan 1879, 138. In Bergey's Manual of Determinative Bacteriology, 8th edn, pp. 416-418. Edited by R. E. Buchanan \& N. E. Gibbons. Baltimore: Williams \& Wilkins.

SHAw, N. (1974). Lipid composition as a guide to the classification of bacteria. Advances in Applied Microbiology 17, 63-108.

Vasstrand, E. N., Hofstad, T., Endresen, C. \& JENSEN, H. B. (1979). Demonstration of lanthionine as a natural constituent of the peptidoglycan of Fusobacterium nucleatum. Infection and Immunity 25, 775-780.

WAlKer, C. B., Ratliff, D., Muller, D., Mandell, R. \& SocranSKY, S. S. (1979). Medium for selective isolation of Fusobacterium nucleatum from human periodontal pockets. Journal of Clinical Microbiology 10, 844-849. 